\title{
Presidentes de Latinoamérica: investigando as interações de estudantes universitários com a série de documentários
}

\section{Rafael Foletto}

\section{Resumo}

Apresentando como objeto imediato da pesquisa a série de documentários Presidentes de Latinoamérica, procura-se investigar a inter-relação de sujeitos comunicantes, no caso, estudantes universitários de diversas nacionalidades, com esse conjunto audiovisual, por meio da vídeo/conversa, vista enquanto procedimento técnico metodológico que permite registrar apropriações a partir das interações de cada indivíduo com os fragmentos do vídeo. Assim, busca-se a realização de diálogos com interlocutores, visando compreender as apropriações, usos, recusas e contextos de interação com o conteúdo do produto midiático pesquisado, no sentido de problematizar que construções simbólicas da América Latina realizam a partir do contato com os filmes, bem como através das suas vivências e trajetórias midiáticas e pessoais.

\section{Palavras-Chave}

América Latina. Documentário. Sujeitos Comunicantes.
Rafael Folett | rafoletto@gmail.com Doutorando em Ciências da Comunicação pela Universidade do Vale do Rio dos Sinos (Unisinos). Bolsista do Conselho Nacional de Desenvolvimento Científico e Tecnológico (CNPq).

\section{Introdução}

Visualiza-se o conjunto audiovisual Presidentes de Latinoamérica como um processo comunicacional complexo que imbrica características, elementos e linguagens do documentário, da televisão e do jornalismo. Ainda, coloca em circulação faz convergir os seus conteúdos para outros formatos, suportes e tecnologias, como a internet. Igualmente, movimenta-se para outros ambientes que não 0 midiático, gerando debates e interações no espaço público, bem como nas significações de sujeitos comunicantes, mediadas por suas memórias, história de vida midiática e visões de mundo.

Nesse sentido, perspectivas teóricas e metodológicas que problematizam a dimensão audiovisual enquanto linguagem complexa se apresentam como significativas para a construção da pesquisa em curso. Para tanto, busca-se compreender a dimensão audiovisual como um processo "no qual apresentam-se, interpretamse, comparam-se, discutem-se, negociam-se significados sobre diversos aspectos da vida 
cotidiana e do mundo social". (BUONANNO, 2006, p. 78-79, tradução nossa), possibilitando investigar os contextos, características e significados que compõem um determinado produto midiático.

Observa-se o documentário enquanto estratégia de comunicação que possibilita manifestar e questionar a realidade. Assim, esse gênero cinematográfico além de possuir uma dimensão artística, técnica e comunicativa, apresenta uma dimensão histórica, política e educativa, sobretudo no espaço latino-americano, ao expressar a riqueza cultural, as conjunturas de crises e os processos de mudança política da região, tornando-se crucial na vida e na comunicação da América Latina. Ainda, percebe-se o documentário como instância potencializadora para 0 desenvolvimento de culturas comunicacionais, cidadãs e políticas inovadoras e transformadoras. Nesse sentido, Gutiérrez Alea (1984) enfatizava a responsabilidade do cineasta na tarefa da conscientização política do espectador, pois 0 cinema mais eficaz enquanto obra de arte 0 é também em sua função mobilizadora.

Pensa-se na construção de uma abordagem teórica e metodológica que possibilite dimensionar e compreender a importância do audiovisual para as culturas populares e étnicas latino-americanas. Ainda, que permita compreender o significado do gênero documentário na construção das experiências e trajetórias não apenas dos sujeitos produtores dessa modalidade audiovisual, mas também dos sujeitos comunicantes, nas suas vivências diárias e inter-relações com a cultura midiática.

Sabe-se que a exploração da dimensão audiovisual no espaço latino-americano é significativa e possui uma riqueza histórica, técnica e estética que fomenta direta ou indiretamente as produções contemporâneas. Inclusive a estratégia dos realizadores da série de documentários investigada, de se nutrir e utilizar imagens e frames de documentários anteriores denota essa memória social do gênero documental na construção das trajetórias midiáticas dos sujeitos comunicantes na região. Enfim, busca-se a construção de uma problematização sobre a inter-relação do gênero documentário com a construção da cultura midiática dos sujeitos, levando em consideração a permeabilidade, sofisticação e diversidade dos meios de comunicação da América Latina.

Desse modo, busca-se no desenvolvimento da investigação, problematizar o processo comunicacional de construção simbólica da América Latina, a partir do conjunto audiovisual e das falas, pensamentos, compreensões e visões de mundo dos interlocutores, por meio da realização de vídeo-conversas, de modo a enriquecer a compreensão da problemática da pesquisa.

\section{Presidentes de Latinoamérica e os novos cenários da região}

Realizada pela pequena produtora argentina Occidente Producciones, o conjunto audiovisual 
Presidentes de Latinoamérica foi exibido em diversas televisões públicas e estatais latinoamericanas $^{1}$, no sistema comunicativo multiestatal TeleSUR e, disponível na internet ${ }^{2}$, apresentando como conteúdo principal uma série de entrevistas com os atuais presidentes da América Latina ${ }^{3}$.

\section{A série de documentários Presidentes de}

Latinoamérica apresenta como mote entrevistas

face a face com 12 Chefes de Estado da região, tendo como objetivo o relato autobiográfico e as reflexões dos principais líderes da América Latina, expondo os pontos chaves para compreender os sofrimentos, as conquistas e as esperanças dos habitantes da região (FILMUS, 2010).

0s relatos em profundidade dos 12 presidentes entrevistados permitem não apenas conhecer as origens, lutas, sonhos e pensamentos dos homens e mulheres que chegaram ao governo em seus países, nos primórdios do século XXI, mas também, o contexto que atravessa a região.

As entrevistas tiveram a condução de Daniel Filmus, ministro da Educação no governo de Néstor Kirchner e atual senador pela província de Buenos Aires. Filmus se integrou a equipe da Occidente Producciones para elaborar os roteiros de perguntas, realizar as pesquisas prévias sobre a vida e a trajetória de cada um dos presidentes entrevistados e, sobre a conjuntura de cada um dos países retratados. Somam-se às entrevistas, depoimentos de pessoas próximas aos mandatários, e de homens e mulheres nas ruas, bem como imagens urbanas e naturais dos países, e materiais históricos referentes à ascensão dos lideres políticos. Da mesma forma, antes e depois das entrevistas, as câmeras e os membros da equipe de produção acompanharam os chefes de Estado em suas diferentes atividades, viagens, percursos e reuniões, mostrando-os fora de seus escritórios, descobrindo aspectos pessoais e matrizes sociais, políticas e culturais de cada um deles.

A situação conflitiva do continente tornou necessário 0 emprego de grandes esforços, tanto para realizar cada uma das entrevistas, quanto para conseguir que 0 encontro com os presidentes não se limitasse a conjuntura política $\mathrm{e}$ econômica do momento. № entanto, e contrariando 0 que muitos dos seus assessores nos advertiram anteriormente a cada diálogo, todos os presidentes concordaram em abordar questões pessoais e políticas que muitas vezes evi-

Por exemplo, na Argentina o conjunto de documentários foi exibido nos canais Encuentro e Siete, no Brasil foi transmitida pela $T V$ Brasil e NBR, no Equador esteve na programação da EC-TV.

Disponível no site: <http://www.presidentestv.com.ar/>.

Os onze presidentes entrevistados na série foram: Álvaro Uribe Vélez, da Colômbia; Cristina Elisabet Fernández de Kirchner, da Argentina; Daniel Ortega, da Nicarágua; Evo Morales Ayma, da Bolívia; Fernando Armido Lugo Méndez, do Paraguai; Hugo Rafael Chávez Frías, da Venezuela; Luiz Inácio Lula da Silva, do Brasil; Michelle Bachelet, do Chile; Óscar Rafael de Jesús Arias Sánchez, da Costa Rica; Rafael Vicente Correa Delgado, do Equador; e Tabaré Ramón Vázquez Rosas, do Uruguai. 
tavam em outros contextos. Alguns demoraram mais para aprofundar a conversa. Vários deles sugeriram nomes de familiares e amigos para serem entrevistados posteriormente e complementar com uma visão mais integral de suas vidas. (FILMUS, 2010, p. 17, tradução nossa).

Ainda, os presidentes entrevistados apresentaram, em suas falas, interesses comuns, bem como a busca de vínculos mais fortes entre eles, procurando compreender a história pessoal um do outro e o contexto dos países do continente, buscando falar com carinho e irmandade da América Latina, pois "nunca como agora a trajetória de vida, as visões e as perspectivas dos presidentes da região estão tão entrelaçadas com as histórias e realidades dos seus povos." (FILMUS, 2010, p. 16, tradução nossa). Desse modo, a série observada permite conhecer parte da vida, da ideologia, da gestão e dos sonhos dos presidentes que estão encabeçando uma significativa transformação na região (FILMUS, 2010).

Igualmente outros elementos da série merecem destaque, como 0 argumento que entrelaça os diálogos cara a cara dos presidentes com outras vozes e 0 manejo das fotografias e imagens e do som, conferindo um tom emotivo às falas dos Chefes de Estado. Desse modo, o conjunto audiovisual se mostra pertinente, sobretudo, por apresentar um panorama de mudanças no horizonte sul-americano, servindo de referencial não apenas para compreender os avanços, conquistas e realizamos dessas novas lideranças, mas também para entender as dificuldades e sofrimentos derivados desse processo. Enfim, a série de documentários Presidentes de Latinoamérica se apresenta como uma foto dessa época de mudanças na América Latina.

As reflexões apontam que o cenário contemporâneo da América Latina, caracterizado por mudanças políticas, sociais, econômicas, culturais e comunicacionais - em boa parte, promovidas pelos atuais governos progressistas da região. Acredita-se que as transformações promovidas por essas novas lideranças políticas propicia que produções como o conjunto audiovisual Presidentes de Latinoamérica circule nos espaços públicos e midiáticos, fomentando o debate não apenas sobre a realidade da região; mas também, referente à constante necessidade de problematizar a comunicação como escopo fundamental para pensar e agir coletivamente em prol de uma cidadania latino-americana.

Igualmente, visualiza-se a série de documentários observada enquanto produto midiático que coloca em circulação uma visão positiva e afirmativa das identidades culturais dos povos latino-americanos, por meio das mensagens que veicula, contribuindo para fortalecer conhecimentos e compreensões da realidade social latino-americana.

\section{Problematizando a questão das interações midiáticas}

Observa-se a necessidade, no campo das Ciências da Comunicação, da inter-relação com distintas 
contribuições e visualizando os processos midiáticos de forma transversal. Dialoga-se com o pensamento de Martín-Barbeiro (2008), que atenta para a necessidade de problematizar os meios a partir das práticas comunicativas, as quais se apresentam inseridas em processos comunicacionais, que atravessam o conjunto do tecido social.

Martín-Barbero (2008) busca pensar as práticas comunicacionais, propondo um modelo que discuta as inserções dos meios no contexto latino-americano, não a partir das mídias, mas sim através de outras mediações, como as práticas culturais. Para 0 autor, é nesse contexto - de fragmentação, de racionalidade econômica, do mundo contemporâneo -, que se situa o papel da mediação massiva, que remeta a tradução contemplada, proporcionando aos sujeitos uma informação que lhes permita dialogar, conversar, exigir, debater sobre o que lhes diz respeito. Em outros termos, significa deslocar os processos comunicativos para o denso e ambíguo espaço da experiência dos sujeitos, localizada em contextos sócio-históricos particulares.

A noção de mediação pressupõe ação reflexiva e é próprio do campo da comunicação. Aos processos técnicos da mídia convém utilizar 0 termo midiatização, que pressupõe a interposição da técnica na relação entre dois indivíduos. Desse modo, os sujeitos sociais perdem o seu ethos, concebendo o ambiente midiatizado como espaço de interação e sociabilidade com os demais indivíduos, pois "um meio de comunicação é um ambiente. Um ambiente é um processo, não é um invólucro. É uma ação e atuará sobre os nossos sistemas nervosos e nas nossas vidas sensoriais, modificando-os por inteiro" (MCLUHAN, 1980, p. 129). Por seu turno, usa-se mediação para destacar processos comunicacionais, midiatizados ou não, que não são neutros, mas sim investidos de sentidos transformadores. Assim, "a mediação é uma instância cultural a partir da qual o público dos meios produz, ao apropria-se deles, o sentido do processo de comunicação". (OLLIVIER, 2008, p. 127, tradução nossa).

Compreende-se que o processo de construção da visão dos indivíduos, necessitaria surgir de um entendimento aprofundado dos grupos sociais e das comunidades que constituem a sociedade, pois, para Armand e Michèle Mattelart (1989), as experiências pessoais se constituem em experiências sociais. Desse modo, a dimensão dos sujeitos é entendida como perspectiva teórica integradora do processo comunicacional e como o momento privilegiado da produção de sentido.

Igualmente, para Lopes, Borelli e Resende (2002, p. 39), a pesquisa com sujeitos diz respeito a "uma tentativa de superação dos impasses a que tem nos levado a investigação fragmentadora e, portanto, redutora do processo de comunicação, em áreas autônomas de análise: da produção, da mensagem, do meio e da audiência”. Porém, Mattelart e Neveu (2004) enfatizam que também é necessário atentar para a questão da produção. 
Ou seja, a ideia é a construção de um olhar interdisciplinar, amplo da realidade que, derivando da abordagem trazida pelos autores, pode ser compreendida como um processo social em fluxo.

Fausto Neto (2006), ao refletir acerca dos efeitos decorrentes dos cenários midiáticos contemporâneos, especialmente no que se refere à sociedade e às novas formas de contato e interação, desenvolve a noção de circulação, que se apresenta como um processo gerador de sentido. Trata-se de uma grande zona de interpenetração de atores, crenças e discursos, redimensionando as instancias de produção e recepção que se interpelam. Assim,

A circulação deixa de ser um elemento 'invisível' ou 'insondável' e, graças a um trabalho complexo de linguagem e técnica, segundo operações de dispositivos, explicita sua 'atividade construcionista', gerando pistas, instituindo novos objetos e, ao mesmo tempo, procedimentos analíticos que ensejem a inteligibilidade do seu funcionamento e dos seus efeitos (FAUSTO NETO, 2010, p. 2).

Dessa forma, a circulação aparece como uma perspectiva interessante para observar as interações sociais potencializadas pelos ambientes midiáticos, ao possibilitar a visualização da forma como os discursos sociais circulam, como ativam efeitos e interpretações e em quais circuitos se movimentam.

Dessa forma, entende-se a necessidade de se desenvolver um olhar metodológico sensível, atento às polaridades, às competências, aos agires, aos sentidos, às lógicas, às visões de mundo dos indivíduos e grupos humanos. Trata-se de uma concepção que centra as suas análises, na observação do papel dos meios no cotidiano dos sujeitos sociais, desenvolvendo principalmente estudos de recepção, mais especificamente da mídia e de programas televisivos de apelo popular.

Sendo assim, observa-se a pertinência de ampliar a problematização sobre a dimensão dos sujeitos, compreendendo as reconfigurações trazidas pelas tecnologias de comunicação, que interrelacionam os papeis de receptor e produtor. Igualmente, compreendendo os atores sociais enquanto sujeitos comunicantes, pois, "as novas formas de narrativa que a internet propõe revitalizam hoje um desejo não alcançado com os meio tradicionais: a formação de leitores críticos" (CORVI DRUETTA, 2009, p. 49). Desse modo, considerando as competências dos interlocutores enquanto leitores, colaboradores e fruidores, através de depoimentos, opiniões, relatos, vivências, manifestações e expressões. Enfim, importar adentrar na dimensão dos sujeitos, ou seja, compreender 0 contexto que 0 permeia e 0 configura. Observando, então, as sociabilidades que se formam os usos que se fazem dos meios e a diversidade de matrizes culturais.

Nesse sentido, pensa-se que as problematizações desenvolvidas pela noção de cidadania comunicativa, referentes ao caráter múltiplo dos sujeitos, compreendendo a necessidade de adoção de estratégias teóricas e metodológicas que 
permitem investigar de forma ampla o processo comunicacional desses sujeitos, em contato com um produto midiático. Enfim, busca-se a partir da inter-relação dos sujeitos com o midiático, pensar como o conjunto audiovisual desencadeia processos de significações sobre a América Latina nos relatos dos interlocutores. Processo que é atravessado por outras vivências e mediações, aspectos os quais, também precisam ser problematizados.

\section{Vídeo/conversa: investigando as significações dos sujeitos}

Pensa-se a vídeo/conversa, enquanto procedimento técnico metodológico permite registrar apropriações a partir das interações de cada sujeito com os fragmentos audiovisuais. Igualmente, possibilita a observação de falas, gestos e sonoridades que constituem os fluxos de apreciações dos materiais simbólicos. Maldonado (2001, p. 50) explicita que "a riqueza 'espontânea', combinada com um registro de áudio e imagens, dota esse instrumento de uma qualidade singular na pesquisa de processos socioculturais em comunicação".

Desse modo, busca-se a aplicação do vídeo/ conversa em diferentes ambiente e espaços, como universidades e cineclubes. Nesse sentido, apresenta-se, na sequência, as reflexões decorrentes de uma primeira experiência de realização desse procedimento metodológico, ocorrida em junho de 2013, na cidade de Santa Maria, possuindo como cenário um grupo de estudantes intercambistas da Universidade
Federal de Santa Maria (UFSM). 0 exercício foi desenvolvido no apartamento de um dos interlocutores, contando com a presença de doze estudantes, oriundos de seis países diferentes, ainda, acredita-se que 0 fato de estarem no ambiente onde vivem, poderia deixar os participantes mais a vontade.

Chegou-se a esse cenário, em primeiro lugar, pela definição do ambiente universitário como um espaço propício para o contato com interlocutores dispostos a problematizar questões referentes a América Latina e ao audiovisual. Ainda, a academia como ambiente de pesquisa já foi experimenta anteriormente através dos questionários exploratórios.

Como roteiro para a realização da atividade, inicialmente, apresentou-se a pesquisa de doutorado, enfatizando a temática e o objeto imediato. Selecionou-se para a exibição trechos dos documentários sobre Cristina Kirchner, Hugo Chávez e Lula, cada um com dez minutos, totalizando trinta minutos de vídeo. Logo após, realizou-se algumas questões sobre América Latina, para nortear o debate entre os participantes, a exemplo de - "a partir dos vídeos e das suas experiências, que realidade da América Latina é apresentada nesses documentários?" E, "esse tipo de vídeo, contribui para compreender questões como a da integração regional?" Através dessas questões abertas e, de outras intervenções e comentários, gerou-se um debate de cerca de uma hora e vinte minutos. 
Os primeiros comentários e reações dos interlocutores surgiram ao longo do episódio da presidenta argentina, $o$ fato de Cristina falar de forma rápida, sem muitas vezes dar tempo para 0 entrevistador fazer uma nova pergunta ou comentário, gerou risos principalmente entre os estudantes da Argentina. No momento em que começou o trecho referente a Hugo Chávez, houve uma imediato rechaço da graduanda estadunidense, manifestado através da expressão - "no, Chávez no". Além disso, os participantes se mostraram muito concentrados e atentos ao conteúdo dos vídeos, realizando raros comentários entre si, durante a exibição dos fragmentos dos documentários.

Ao longo do debate, as participações mais intensas e protagonistas foram das estudantes de Administração e Serviço Social, María e Candela. Aliás, a participação dos argentinos, por estarem em maior número, foi mais significativa. Enquanto que as estudantes do Chile e do Uruguai fizeram comentários mais pontuais e, os acadêmicos dos Estados Unidos e México interagiram somente quando foram questionados diretamente. Após os primeiros 30 minutos das atividades, Ángel, da Espanha, passou a participar de forma mais intensa, falando por mais tempo que os outros e buscando contextualizar as suas manifestações, ilustrando os seus comentários com situações pessoais e suas vivências no Brasil e na Europa.

Em geral, os interlocutores observaram que, apesar dos vídeos possuírem uma boa qualidade estética e de produção, apresentando imagens interessantes da América Latina, não apresentam a realidade da região de forma ampla. Na visão deles, não existe a Pátria Grande, fazendo alusão ao termo cunhado por Chávez na sua entrevista, para descrever a realidade contemporânea latino-americana. Visão que pode ser ilustrada pelas seguintes falas: "é difícil pensar uma pátria grande, já que a realidade da América Latina não é a mesma em cada país" (Mariana). "Vemos coisas interessantes sobre as suas vidas, mas não mostram a realidade" (Natalia).

Em relação a forma como os presidentes são retratados no conjunto audiovisual, os interlocutores apresentaram compreensões diferentes sobre cada um dos Chefes de Estado entrevistados. Exceto em relação a Lula, que para eles foi o mais coerente ao falar sobre a sua trajetória pessoal, a realidade do Brasil e da América Latina. "A expressão de Lula, parece de uma pessoa de bom caráter, condizente com as suas falas com sua forma de ser. Simplesmente não gosto de Cristina, não sei o que fez, nunca tinha a visto antes" (Óscar).

Nesse sentido, a entrevista e a postura da presidenta da Argentina foi a que recebeu mais críticas dos entrevistados. Segundo os interlocutores, principalmente os argentinos, Cristina Fernández não pareceu natural nas suas colocações, apresentando-se de forma distinta a realidade que eles vivenciam. "Cristina não é 
coerente, possui uma postura diferente de Lula e Chávez. Ela não respondeu nenhuma pergunta" (María). "Cristina falou que não é preto ou branco, mas é sim" (Carla). Ainda, para essas duas participantes, esse tipo de fala da presidenta reflete em decisões políticas tomadas por ela, que contribuem para construir um sentimento de isolamento econômico da Argentina em relação aos outros países da região. "A Argentina distante do mundo, que não confia no país para investir" (María). "Argentina hoje é só vaca e soja" (Carla).

A figura e a entrevista de Hugo Chávez se apresentou como a principal fonte de discussão entre os participantes. Nessa perspectiva, observa-se que nas falas dos interlocutores, em sua maioria, preponderou uma visão do expresidente venezuelano construída através de matrizes reforçadas pelos meios de comunicação hegemônicos da região e do mundo, que 0 apresentam como um ditador. "Chávez era um ditador, a forma de conseguir o ideal que defendia é diferente da fala dele. Ele não é muito democrático. Acho que se desvirtua quando se fica muito tempo no poder, pois o poder afeta as pessoas" (María).

Tenho amigos na Venezuela, a opinião deles e de muitas pessoas dos Estados Unidos é a de que não gostam de Chávez, a ideia é de um país muito corrupto, a percepção é de uma pessoa muito corrupta, um ditador. As pessoas votam em Chávez, mas na realidade não querem votar. É, como Franco [ditador espanhol], trouxe muitas coisas boas, mas no fim usou seu poder para muitas coisas ruins (Kelsey).

No entanto, em outras falas, na qual igualmente preponderou representação preponderante de Hugo Chávez como um ditador, essa construção foi apresentada de forma mais reflexiva e relativizada. "Não digo que tudo o que Chávez fez pela Venezuela está mal feito, mas é uma ditadura, pois seu poder chega ao limite da democracia, assim como a corrupção na Venezuela" (Ángel).

Ainda, dois interlocutores apresentaram uma concepção diferente do ex-presidente venezuelano, observando de forma mais positiva a sua trajetória, lideranças e ações. "O que gosto de Chávez era o seu discurso anti-imperialista, anti-consumista, sempre foi bem explicito na sua postura" (Candela). "Chávez foi o maior líder dos últimos tempos na América Latina, tinha uma liderança muito grande" (Franco).

De maneira geral, os entrevistados compreenderam que o conjunto audiovisual se constitui como um interessante material para compreender as trajetórias pessoais e políticas dos presidentes entrevistados. Ainda, para eles, os vídeos se apresentam um olhar distinto de outras produções midiáticas no que concerne a forma como retrata essas lideranças políticas, bem como a América Latina. "Todos eles mostram uma parte mais humana dos presidentes, 
que não é algo que vemos sempre. Mas pode ser positivo ou negativo" (Mariana). Candela complementa observando o que a trajetória das atuais lideranças políticas latino-americanas " $n \tilde{a}$ o garante que por serem de classes populares governem para os trabalhadores. Exemplo disso são as políticas de repressão policial na Argentina e no Brasil, muitas vezes contra os trabalhadores".

Com relação a isso, os participantes apontaram que o panorama da América Latina tem mudado recentemente, sobretudo, com o surgimento dessas novas lideranças políticas. "Brasil e América Latina crescendo, assustando o exterior, com muito poder, muita população e muita produção, possuindo um peso muito grande no mundo contemporâneo" (Ángel).

\section{Antes não existia comércio interno e} produção interna, era tudo importado.

Também, os presidentes não se relacionavam. Houve muito luta para mudar isso e, isso sim representa aos latino-americanos, essa busca pela mudança. Acredito que os vídeos mostram que há uma mudança (Hernán).

Outra interlocutora aponta que, no entanto, essas mudanças não são percebidas por grande parte da população. Devido, sobretudo, aos meios de comunicação hegemônicos que destorcem os fatos. Contudo, o conjunto audiovisual pode ser observado como uma possibilidade da população latino-americana ter contato com algumas das mudanças que vem acontecendo no continente. Para ela,

$$
\begin{aligned}
& \text { faltam muitas coisas para fazer, mas vendo o } \\
& \text { vídeo, tenho esperança de que vai acontecer. } \\
& \text { As pessoas não compreendem, as vezes, os } \\
& \text { projetos que estão fazendo os presidentes, } \\
& \text { pois se não acontece já, não estão fazendo } \\
& \text { nada, mas são projetos que vão ter reflexo no } \\
& \text { futuro (Carla). }
\end{aligned}
$$

Ainda, outro aspecto que foi levantado durante as discussões do vídeo/conversa diz respeito a integração dos países nesse novo contexto latino-americanos. Para Carla, "os jovens tem mais vontade de participar da política, pois se identificam com esse projeto de uma América Latina unida". Igualmente, "vejo a importância da consciência cidadã, pois as novas leis nãa são fruto da vontade dos governos, mas dos movimentos sociais, que militam todos os dias porque querem um determinado projeto. As pessoas veem a política como algo bom" (Candela). No entanto, Evelyn aponta que com 0 desenvolvimento de políticas de privatização de empresas públicas, 0 Chile caminha na contramão da conjuntura atual da América Latina, "os políticos chilenos tentam imitar a forma de governo da Europa e dos Estados Unidos e, não da América Latina. Não estão conectados com o contexto da região".

Acredita-se que essa experiência inicial com a técnica da vídeo/conversa se apresentou 
como significativa para as processualidades metodológicas da investigação, ao colocar em perspectiva vozes, opiniões, problematizações e diálogos de uma diversidade de sujeitos comunicantes, discutindo coletivamente elementos e aspectos da realidade que os rodeiam, inter-relacionados com 0 vídeo exibido. Enfim, dialoga-se com Lopes, Borelli e Resende (2002), que ao utilizarem recursos semelhantes ao vídeo/ conversa, como o grupo de discussão e telenovela reeditada, enfatizam a riqueza do material gerado pela discussão, na qual o assunto é tratado por meio de diferentes ângulos e abordagens, trazendo distintos discursos e significações por meio das assimetrias e divergências de opiniões e posturas dos participantes.

Ainda, observaram-se algumas dificuldades relativas ao emprego do vídeo/conversa, como a seleção e recorte das partes dos vídeos as serem exibidas, em se tratando de um conjunto audiovisual extenso. Para tanto, visualizase na necessidade da utilização de distintos procedimentos metodológicos para a construção de uma análise ampla das manifestações dos sujeitos comunicantes, envolvendo a tanto os sentidos produzidos pelos participantes, quanto os sentidos ofertados pela seleção audiovisual utilizada para instigar a discussão entre os interlocutores.

\section{Reflexões finais}

Pensa-se que os documentários investigados se apresentam como relevantes porque oferecem importantes ângulos para se observar as mudanças que vêm acontecendo no continente, igualmente a forma como essas transformações são apresentadas em produtos midiáticos. Destaca-se, ainda, a possibilidade de as mensagens vinculadas pela série ressaltarem questões como a identidade cultural e a constituição da cidadania comunicativa na região e a construção de ações positivas de integração regional de modo a contribuir para 0 fortalecimento de saberes sistemáticos e profundos sobre a realidade sociocultural e política da América Latina.

Igualmente, através do exemplo do conjunto de documentários Presidentes de Latinoamérica, visualiza-se a possibilidade de mudança, de participação e de "realizar produções culturais transformadoras sem a necessidade de ter grandes infraestruturas industriais, laboratórios caros e sofisticados e procedimentos intelectuais de circulação restrita" (MALDONADO, 2008, p. 35).

Visualiza-se a necessidade da adoção de estratégias de investigação que priorizem uma visão multidimensional das problemáticas sociais, históricas e políticas relevantes para compreender as dinâmicas da realidade sociocultural contemporânea. Desse modo, colocando em perspectiva conceitos e abordagens que ficariam incompletos se ancorados em apenas um único ponto do processo comunicacional. E, da mesma forma, possibilitando a utilização de diferentes técnicas para a análise do problema-objeto. 
Sendo assim, busca-se compreender as apropriações realizadas por uma diversidade de sujeitos em relação a América Latina midiatizada pelo ciclo de documentários. Para tanto, acreditase que a vídeo/conversa se apresentam como procedimento de pesquisa relevante para a compreensão da produção de significações tanto individuais, quanto coletivas, permitindo a participação de vários sujeitos, contribuindo para aprofundar e detalhar qualitativamente pensamentos, opiniões, sentimentos, emoções, atitudes em um ambiente de diálogo e debate sobre aspectos e elementos relativos ao produto investigado, bem como em relação aos objetivos da pesquisa. Assim, acredita-se que essa experiência empírica contribui para investigar os sentidos produzidos e as apropriações realizadas pelos interlocutores, no processo de inter-relação com a América Latina midiatizada pelo conjunto de documentários, contribuindo também para identificar as mediações que constituem e atuam no processo de geração de significações, considerando aspectos das trajetórias políticos, sociais, históricos e culturais dos sujeitos contatados. Ainda, pensa-se que esse procedimento empírico contribuirá para ampliar e aperfeiçoar a compreensão das características audiovisuais que produzem especificidade aos documentários investigados.

\section{Referências}

BUONANNO, M. El drama televisivo: identidad y contenidos sociales. Barcelona: Gedisa, 1999.
CORVI DRUETTA, Delia. Internet, a aposta na diversidade. In: FRAGOSO, S.; MALDONADO, A. E. Internet na América Latina. São Leopoldo: Unisinos; Sulina, 2009. p. 41-58.

FAUSTO NETO, A. Midiatização, prática social - prática de sentido. In: ENCONTRO ANUAL DA COMPÓS, 15., 2006. Bauru. Anais... Bauru: Unesp, 2006.

FAUSTO NETO, A. A circulação além das bordas. In: FAUSTO NETO, A.; VALDETTARO, S. (Org.).

Mediatización, sociedad y sentido. Rosário: Departamento de Ciencias de la Comunicación - UNR, 2010, p. 2-17.

FILMUS, D. Presidentes: voces de América Latina. Buenos Aires: Aguilar; Altea; Taurus; Alfaguara, 2010.

GUTIÉRREZ ALEA, T. Dialética do espectador: seis ensaios do mais laureado cineasta cubano. São Paulo: Summus, 1984.

LOPES, M. I.V.; BORELLI, S. H. S.; RESENDE, V. da R. Vivendo com a telenovela: mediações, recepção, teleficcionalidade. São Paulo: Summus, 2002.

MALDONADO, A. E. Teorias da Comunicação na

América Latina: enfoques, encontros, apropriações da obra de Verón. São Leopoldo: Editora Unisinos, 2001.

MALDONAD0, A. E. A perspectiva transmetodológica na conjuntura de mudança civilizadora em inícios do século XXI. In: MALDONADO, A. E.; BONIN, J.; ROSÁRIO, N. (Org.). Perspectivas metodológicas em comunicação: desafios na prática investigativa. João Pessoa: Editora UFPB, 2008. p. 27-54.

MARTÍN-BARBERO, J. Dos meios às mediações: comunicação, cultura e hegemonia. Rio de Janeiro: Editora UFRJ, 2008.

MATTELART, A.; MATTELART, M. 0 carnaval das imagens: a ficção na TV. São Paulo: Brasiliense, 1989. MATTELART, A.; NEVEU, E. Introdução aos estudos culturais. São Paulo: Parabola, 2004. 
MCLUHAN, M. 0 meio é a mensagem. In: MCLUHAN, S.; STAINES, D. (Org.). McLuhan por McLuhan: conferências e entrevistas. Rio de Janeiro: Ediouro, 2005. p. 111-142.

OLLIVIER, B. Medios y mediaciones. Revista

Anthropos: Huellas del Conocimiento, n. 219, p. 121131, 4/2008. 
Presidentes de Latinoamérica: investigating the universitary students interactions with a set of documentaries

Presidentes de Latinoamérica: investigando las interacciones de estudiantes universitarios con la serie documental

\section{Abstract}

Presenting the set of documentaries Presidentes de Latinoamérica as an object of research, we investigate the relation of communicating subjects, in this case, universitary students of several different nationalities, with this set of films, through video and conversation, as a methodological technical procedure that allows to register appropriations based on the interactions of each person with fragments of the video. This way, is intended to take notice of the dialogue between these students, aiming to understand the appropriations, uses, refuses and contexts of interaction with the researched subject, meaning to point what symbolic constructions of Latin America they create based on the contact with these films, as well through their experiences with this kind of media and personal interactions as well.

\section{Keywords}

Latin America. Documentary. Communicating Subjects.

\section{Resumen}

Presentando como objeto inmediato de la investigación la serie documental Presidentes de Latinoamérica, se busca investigar la inter-relación de sujetos comunicantes, en el caso, estudiantes universitarios de diversas nacionalidades, con ese conjunto audiovisual, por medio de la vídeo/ conversación, usada mientras procedimiento técnico-metodológico que permite registrar apropiaciones a partir de las interacciones de cada individuo con los fragmentos del vídeo. Así, se busca la realización de diálogos con interlocutores, visando comprender las mirada, usos, rechazas y contextos de interacción con el contenido del producto mediático investigado, en el sentido de analizar que construcciones simbólicas de la América Latina realizan a partir del contacto con las películas, así como a través de sus vivencias y trayectorias mediáticas y personales.

Palabras-Clave

América Latina. Documental. Sujetos comunicantes. 


\section{Expediente}

A revista E-Compós é a publicação científica em formato eletrônico da Associação Nacional dos Programas de Pós-Graduação em Comunicação (Compós). Lançada em 2004, tem como principal finalidade difundir a produção acadêmica de pesquisadores da área de Comunicação, inseridos em instituições do Brasil e do exterior.

\section{E-COMPÓS I www.e-compos.org.br I E-ISSN 1808-2599}

Revista da Associação Nacional dos Programas

de Pós-Graduação em Comunicacão.

Brasília, v.17, n.2, mai./ago. 2014.

A identificação das edições, a partir de 2008

passa a ser volume anual com três números.

\section{CONSELHO EDITORIAL}

Afonso Albuquerque, Universidade Federal Fluminense, Brasil Alberto Carlos Augusto Klein, Universidade Estadual de Londrina, Brasil Alex Fernando Teixeira Primo, Universidade Federal do Rio Grande do Sul, Brasil Rio Grande do Sul, Brasi

Ana Gruszynski, Universidade Federal do Rio Grande do Sul, Brasil Ana Silvia Lopes Davi Médola, Universidade Estadual Paulista, Brasil André Luiz Martins Lemos, Universidade Federal da Bahia, Brasi Ângela Freire Prysthon, Universidade Federal de Pernambuco, Brasil Antônio Fausto Neto, Universidade do Vale do Rio dos Sinos, Brasil Antonio Carlos Hohlfeldt, Pontifícia Universidade Católica do Rio Grande do Sul, Brasil Antonio Roberto Chiachiri Filho, Faculdade Cásper Líbero, Brasi Arlindo Ribeiro Machado, Universidade de São Paulo, Brasil Arthur Autran Franco de Sá Neto, Universidade Federal de São Carlos, Brasil Benjamim Picado, Universidade Federal Fluminense, Brasil César Geraldo Guimarães, Universidade Federal de Minas Gerais, Brasil Cristiane Freitas Gutfreind, Pontifícia Universidade Católica do Rio Grande do Sul, Brasil Denilson Lopes, Universidade Federal do Rio de Janeiro, Brasil Denize Correa Araujo, Universidade Tuiuti do Paraná, Brasi Edilson Cazeloto, Universidade Paulista , Brasil

Eduardo Vicente, Universidade de São Paulo, Brasil Eneus Trindade, Universidade de São Paulo, Brasil Erick Felinto de Oliveira, Universidade do Estado do Rio de Janeiro, Brasi Florence Dravet, Universidade Católica de Brasília, Brasil Gelson Santana, Universidade Anhembi/Morumbi, Brasi Gilson Vieira Monteiro, Universidade Federal do Amazonas, Brasil Gislene da Silva, Universidade Federal de Santa Catarina, Brasil Guillermo Orozco Gómez, Universidad de Guadalajara Gustavo Daudt Fischer, Universidade do Vale do Rio dos Sinos, Brasil Hector Ospina, Universidad de Manizales, Colômbia Herom Vargas, Universidade Municipal de São Caetano do Sul, Brasil Ieda Tucherman, Universidade Federal do Rio de Janeiro, Brasil Inês Vitorino, Universidade Federal do Ceará, Brasil Janice Caiafa, Universidade Federal do Rio de Janeiro, Brasil Jay David Bolter, Georgia Institute of Technology Jeder Silveira Janotti Junior, Universidade Federal de Pernambuco, Brasi João Freire Filho, Universidade Federal do Rio de Janeiro, Brasil John DH Downing, University of Texas at Austin, Estados Unidos Ana Carolina Damboriarena Escosteguy, Pontifícia Universidade Católica do

José Afonso da Silva Junior, Universidade Federal de Pernambuco, Brasil José Carlos Rodrigues, Pontifícia Universidade Católica do Rio de Janeiro, Brasil José Luiz Aidar Prado, Pontifícia Universidade Católica de São Paulo, Brasil José Luiz Warren Jardim Gomes Braga, Universidade do Vale do Rio dos Sinos, Brasil Juremir Machado da Silva, Pontifícia Universidade Católica do Rio Grande do Sul, Brasil Laan Mendes Barros, Universidade Metodista de São Paulo, Brasil Lance Strate, Fordham University, USA, Estados Unidos Lorraine Leu, University of Bristol, Grã-Bretanha Lucia Leão, Pontifícia Universidade Católica de São Paulo, Brasil Luciana Panke, Universidade Federal do Paraná, Brasil Luiz Claudio Martino, Universidade de Brasília, Brasil Malena Segura Contrera, Universidade Paulista, Brasil Márcio de Vasconcellos Serelle, Pontifícia Universidade Católica de Minas Gerais, Brasil Maria Aparecida Baccega, Universidade de São Paulo e Escola Superior de Propaganda e Marketing, Brasil Maria das Graças Pinto Coelho, Universidade Federal do Rio Grande do Norte, Brasil Maria Immacolata Vassallo de Lopes, Universidade de São Paulo, Brasil Maria Luiza Martins de Mendonça, Universidade Federal de Goiás, Brasil Mauro de Souza Ventura, Universidade Estadual Paulista, Brasil Mauro Pereira Porto, Tulane University, Estados Unidos Nilda Aparecida Jacks, Universidade Federal do Rio Grande do Sul, Brasil Paulo Roberto Gibaldi Vaz, Universidade Federal do Rio de Janeiro, Brasil Potiguara Mendes Silveira Jr, Universidade Federal de Juiz de Fora, Brasil Renato Cordeiro Gomes, Pontifícia Universidade Católica do Rio de Janeiro, Brasil Robert K Logan, University of Toronto, Canadá

Ronaldo George Helal, Universidade do Estado do Rio de Janeiro, Brasil Rosana de Lima Soares, Universidade de São Paulo, Brasi Rose Melo Rocha, Escola Superior de Propaganda e Marketing, Brasil Rossana Reguillo, Instituto de Estudos Superiores do Ocidente, Mexico Rousiley Celi Moreira Maia, Universidade Federal de Minas Gerais, Brasi Sebastião Carlos de Morais Squirra, Universidade Metodista de São Paulo, Brasil Sebastião Guilherme Albano da Costa, Universidade Federal do Rio Grande do Norte, Brasil

Simone Maria Andrade Pereira de Sá, Universidade Federal Fluminense, Brasi Tiago Quiroga Fausto Neto, Universidade de Brasília, Brasil Suzete Venturelli, Universidade de Brasília, Brasil Valerio Fuenzalida Fernández, Puc-Chile, Chile Veneza Mayora Ronsini, Universidade Federal de Santa Maria, Brasil Vera Regina Veiga França, Universidade Federal de Minas Gerais, Brasil

\section{COMISSÃO EDITORIAL}

Cristiane Freitas Gutfreind I Pontifícia Universidade Católica do Rio Grande do Sul, Brasil Irene Machado I Universidade de São Paulo, Brasil

Jorge Cardoso Filho I Universidade Federal do Reconcavo da Bahia, Brasil / Universidade Federal da Bahia, Brasil

CONSULTORES AD HOC

Adriana Amaral, Universidade do Vale do Rio dos Sinos, Brasil

Alexandre Rocha da Silva, Universidade Federal do Rio Grande do Sul, Brasi Arthur Ituassu, Pontifícia Universidade Católica do Rio de Janeiro, Brasil Bruno Souza Leal, Universidade Federal de Minas Gerais, Brasil Elizabeth Bastos Duarte, Universidade Federal de Santa Maria, Brasil Francisco Paulo Jamil Marques, Universidade Federal do Ceará, Brasil Maurício Lissovsky, Universidade Federal do Rio de Janeiro, Brasil Suzana Kilpp, Universidade do Vale do Rio dos Sinos, Brasil Vander Casaqui, Escola Superior de Propaganda e Marketing, Brasil

EDIÇÃO DE TEXTO E RESUMOS I Susane Barros SECRETÁRIA EXECUTIVA I Helena Stigger EDITORAÇÃo ELETRÔNICA I Roka Estúdio
COMPÓS I www.compos.org.br

Associação Nacional dos Programas de Pós-Graduação em Comunicação

Presidente

Eduardo Morettin

Universidade de São Paulo, Brasil

eduardomorettin@usp.br

Vice-presidente

Inês Vitorino

Universidade Federal do Ceará, Brasil

ines@ufc.br

Secretária-Geral

Gislene da Silva

Universidade Federal de Santa Catarina, Brasil

gislenedasilva@gmail.com 